\title{
A Comprehensive Review of Cutaneous Leishmaniasis in Sri Lanka and Identification of Existing Knowledge Gaps
}

\author{
Anjalie Amarasinghe ${ }^{1}$ (D) Susiji Wickramasinghe ${ }^{1}$ (I)
}

Received: 2 August 2019 / Accepted: 24 January 2020 / Published online: 12 February 2020

(c) Witold Stefański Institute of Parasitology, Polish Academy of Sciences 2020

\begin{abstract}
Purpose Sri Lanka is endemic to cutaneous leishmaniasis and reported as the latest focus of leishmaniasis in the Asian subcontinent. Annually, the number of leishmaniasis cases is increasing; therefore, more efficient diagnostic tools, treatment methods and effective prevention measures are indispensable. For this reason, many studies were conducted regarding leishmaniasis infections in Sri Lanka; however, some areas need more attention. Thus, in this review, we comprehensively discussed the studies on leishmaniasis carried out in Sri Lanka.

Methods Published articles on leishmaniasis in Sri Lanka were searched on PubMed, Google Scholar and ResearchGate databases. Inclusion criteria for the articles were based on keyword searches including 'Leishmaniasis in Sri Lanka', 'Leishmaniasis vector in Sri Lanka', 'Sandfly species in Sri Lanka', 'Leishmaniasis epidemiology in Sri Lanka' which are publicly accessible as of 15 th July 2019.

Results In this study, we evaluated and summarized the leishmaniasis reports in Sri Lanka and mainly focused on clinical presentation of leishmaniasis infection, genetic characteristics of Leishmania donovani Sri Lankan strain, geographical distribution and associated environmental factors, immunological aspects of the infection, vector, reservoir host, risk factors, diagnosis and treatment, and prevention and control. Furthermore, we identified the areas where further research is needed to fill the essential knowledge gaps.

Conclusions Leishmaniasis has become a critically important parasitic infection in Sri Lanka, whereas the significant clinical form is cutaneous leishmaniasis. Prevalence of the leishmaniasis infections is reported from all the districts of the country. Therefore, more studies are essential to be carried out to fill the existing knowledge gaps emphasized in this review.
\end{abstract}

Keywords Cutanaous leishmaniasis $\cdot$ Sri Lanka $\cdot$ Leishmania donovani $\cdot$ Phlebotomus spp. Sergentomia spp.

\section{Introduction}

Leishmaniasis is a parasitic infection with significant clinical and epidemiological diversity. This disease caused by the protozoa in the genus Leishmania, and transmitted by the bite of an infected female sandfly. There are three main categories of leishmaniasis clinical manifestation viz. cutaneous (CL), visceral (VL), and mucocutaneous leishmaniasis (MCL). Typically, CL is caused by Old World Leishmania

Susiji Wickramasinghe

susijij@pdn.ac.lk; susijijp@yahoo.co.jp

Anjalie Amarasinghe

anjalie.a22@gmail.com

1 Department of Parasitology, Faculty of Medicine, University of Peradeniya, New Galaha Road, Peradeniya 20400, Sri Lanka species such as Leishmania major, L. tropica, and L. aethiopica. The VL is caused by Leishmania donovani and $L$. infantum. The New World Leishmania species, L. braziliensis cause MCL [1]. However, L. donovani is responsible for both cutaneous and visceral leishmaniasis in Sri Lanka.

Leishmaniasis represents a significant world health problem. It is endemic to Asia, Africa, parts of South America, Central America, the Mediterranean, and affects nearly 89 countries [2]. Worldwide 12-15 million people are infected; with 1-2 million new cases. Annually, infections cause about 70,000 deaths [3]. About 350 million worldwide are at risk of acquiring leishmaniasis. World Health Organization (WHO) pronounced leishmaniasis as one of the seven most important tropical diseases in the world [2].

Sri Lanka is endemic to CL and reported as the latest focus of leishmaniasis in the Asian subcontinent [4]. Cutaneous leishmaniasis is the dominant clinical form found in 
Sri Lanka [5]. Leishmaniasis was pronounced as a notified disease in 2008 by the Ministry of Health. Annually, a considerably high number of cutaneous leishmaniasis cases were reported from many districts in Sri Lanka. In the year 2018, The Epidemiology Unit reported 3271 leishmaniasis cases (Epidemiology Unit, Ministry of Health, 2019) [6]. Annually, the number of leishmaniasis patients is getting increased; therefore, more efficient diagnostic tools, treatment methods and effective prevention measures are indispensable. For this reason, many studies were conducted regarding leishmaniasis infections in Sri Lanka; however, some areas need more attention. Thus, in this review, we comprehensively discussed the studies carried out in Sri Lanka concerning leishmaniasis, which are publicly accessible as of 15th July 2019, and the knowledge gaps are highlighted where applicable.

\section{Cutaneous Leishmaniasis in Sri Lanka}

Sri Lanka is endemic for CL and it is the primary clinical form found [4,5]. Cutaneous leishmaniasis is caused by $L$. donovani zymodeme MON-37; the same species that cause $\mathrm{VL}$, which is a fatal condition in South-East Asia, Latin America and Eastern Africa [5, 7]. In Sri Lanka, L. donovani seems to be the only species that cause CL [8]. However, there are multiple strains within the group of local L. donovani and currently it is not possible to predict the diversity complications that could occur in the future [9].

The first case of locally acquired CL in Sri Lanka was reported from the Southern Province in 1992 [10]. The CL was identified as a spectral disease similar to leprosy [11]. The histological groups of CL are ranging from I to IV [11]. A recent study identified a separate clinical entity within the profile of CL as atypical skin manifestations (ACL) [12]. Clinical and geographical distribution patterns of ACL and its response to the treatments were different from those of classical CL [12]. Therefore, ACL requires careful attention to prevent its silent and excessive transmission.

\section{Visceral and Mucocutaneous Leishmaniasis in Sri Lanka}

Based on histopathological and haematological findings, the first locally acquired VL case in Sri Lanka was reported from the Anuradhapura district [13]. Since then, only a few cases of confirmed VL were reported from the country [14]. First isolation and identification of autochthonous VL strain from Sri Lanka were in 2010 [15]. At least a part of locally identified strains of $L$. donovani possesses the ability to cause visceral infections [16]. Also, there is evidence to believe that the prevalence of VL will increase in Sri Lanka $[17,18]$.

The first report of mucosal tissue localization of leishmaniasis in Sri Lanka was in 2005 [19]. Co-infection of MCL in a patient with tuberculosis lymphadenitis and inherent immune deficiency was then reported in 2010 [20]. Clinical features of this case were similar to MCL caused by $L$. donovani in India [21]. These atypical MCL cases did not show a primary skin lesion. Therefore, they were different from the true MCL caused by L. braziliensis [19].

\section{Genetic Uniqueness of $L$. donovani in Sri Lanka that Cause CL and VL}

The multilocus enzyme electrophoresis (MLEE) revealed that $L$. donovani zymodeme MON-37 is responsible for both cutanaous and visceral leishmaniasis in Sri Lanka [15]. Also, MLEE identified that the $6 P G D H$ gene sequence of these $L$. donovani zymodeme MON-37 strains that cause VL and CL are the same [15, 17]. Furthermore, a study conducted using BALB/c mice identified the $L$. donovani in Sri Lanka that cause $C L$ was severely attenuated for survival in visceral organs compared to $L$. donovani that cause $\mathrm{VL}$ in the country [22]. However, it acquired the ability to cause CL in humans. Furthermore, this study reports SNPs and protein level variations as the most likely factors for this disease tropism and pathology differences. The same study identified the expression of $\operatorname{Rag} C$ and $A 2$ genes may contribute to the different pathologies caused by the $L$. donovani in Sri Lanka [22].

The dermotropic nature of $L$. donovani in Sri Lanka was confirmed by a long-term patient follow-up study [23]. This study reports the absence of signs and symptoms of visceralization in these patients. Intra-dermal infection of mice with live $L$. donovani Sri Lankan isolates did not lead to visceralization or systemic spread of infection [23]. A study conducted on $\mathrm{BALB} / \mathrm{c}$ mice has identified the subcutaneous immunization with the live $L$. donovani isolate causing CL in Sri Lanka was associated with significantly decreased liver parasite burden following challenge with the virulent Sri Lankan VL isolate [24]. This could indicate protective immunity against VL among humans in Sri Lanka since the resolution of cutaneous lesions is more common. This may be the reason for the low levels of VL observed in Sri Lanka. Furthermore, this study indicates this method of immunization can be useful in vaccine development efforts for visceral leishmaniasis worldwide [24].

However, the complete genetic characteristics of the $L$. donovani zymodeme MON-37 that cause VL and CL in Sri Lanka is not yet fully resolved. Therefore, it is unknown whether the same or different sub-strains of $L$. donovani MON-37 are responsible for VL and CL in Sri Lanka. 
Also, it is required to identify the immune factors in the host to understand the aspects responsible for different tropism shown by the same $L$. donovani strain. Research can be further developed to compare and contrast the genetic characteristics of the L. infantum (syn. L. chagasi) species that cause VL in the new world and $L$. donovani zymodeme MON-37 strain that causes VL in Sri Lanka.

\section{Geographical Distribution}

The first detailed survey conducted regarding leishmaniasis indicated a high prevalence in southern and northern regions of the island [25]. A study carried out to analyze epidemiological data showed that almost $90 \%$ of the leishmaniasis cases reported between 2009 and 2016 were from Anuradhapura, Hambantota, Polonnaruwa, Kurunegala, and Matara as endemic districts (Fig. 1). They have identified a correlation between several climatic factors and increased infections [26]. The same study identified that the highest incidence was from the Anuradhapura and Hambantota districts (Fig. 1). These districts indicate an endemic hotspot affecting the North Central and Southern Provinces of Sri Lanka as its epicenter [26]. In Polonnaruwa district, cases of CL reported from 2008 to 2012 showed apparent spatial and temporal clustering [27]. Also, a study identified increased transmission of CL from endemic to non-endemic areas [28].

Over the last decade, many cases of CL were reported from the endemic areas (North Western, North Central, and Southern provinces) $[10,27,28]$. CL was identified as an emerging public health problem in the Matara district in the Southern Province (Fig. 1) [29]. A recent study identified first evidence for two independent and different leishmaniasis transmission foci in Sri Lanka; north and south as two preexisting foci [9]. In the northern provinces of the country, the transmission of the parasite is mostly outdoors, and in the south, it seems to be peridomestic [25]. Leishmania infections are increasing in epidemic proportions in Mulathivu, Monaragala and Kurunegala (Fig. 2) [26, 30]. Also, a considerably high number of patients were reported from Matale and Kandy (Intermediate and wet zones in the Central Province) (Fig. 2) [28].

\section{Association with Climate and Weather Conditions}

According to a comprehensive epidemiological study conducted by Galgamuwa et al. [26], maximum temperature, humidity, wind speed, and wind gust are the significantly associated climatic variables with leishmaniasis in endemic regions. Rainfall is negatively correlated with leishmaniasis infections in endemic regions [26]. The highest incidence of leishmaniasis patients were found in less than $100 \mathrm{~m}$ above sea level. The incidence of leishmaniasis at high altitudes is very low compared to the cases identified from areas situated at low altitudes. The environmental conditions in high altitude regions such as low temperature and low humidity are unfavourable for the breeding of sandflies. In contrast, breeding sites with favourable conditions are abundant in low altitude areas [8, 26, 31].

The incidence of leishmaniasis in Hambantota and Matara districts has shown a significant positive correlation with monthly average and maximum temperatures [26]. A study identified that $L$. infantum and $L$. brazilliensis develop well between 20 and $26^{\circ} \mathrm{C}$ in sandflies [32]. This study can extend to identify the optimum temperatures required for the development of $L$. donovani in sandfly species in Sri Lanka. Furthermore, the population dynamics of sandfly species in Sri Lanka concerning climatic variables can be investigated to identify the factors that would increase the sandfly population.

Leishmaniasis has a seasonal pattern with an increased number of infections in dry seasons [26, 27]. During droughts, people in rural areas tend to cluster around natural water supplies and by that, their exposure towards sandfly bites increases. Also, increasing movements of humans in cultivated and forest areas during dry seasons might contribute to an increase in the exposure to sandfly bites [26].

\section{Immunological and Genetic Significances of $\mathrm{CL}$ in Sri Lanka}

Studies have revealed altered immunological responses in CL patients. Higher levels of expression of cytokines IFN$\gamma, \mathrm{IL}-4, \mathrm{IL}-11$ and IL-12p40 were identified in CL patients compared to healthy volunteers. Th1 type cellular immune responses (IFN- $\gamma$ and IL-12p40) had higher expression levels compared to Th2 (IL-4) and IL-11 in CL patients. The expression of IFN- $\gamma$ showed a significant association with the duration of the lesion. Wet CL lesions (moist ulcers with purulent exudates) showed significantly higher expression of IL-4, IL-11 and IL-12p40 compared to dry lesions (crusted scabs). Papulonodular lesions showed significantly higher expression of IFN- $\gamma[33,34]$. Significantly elevated tissue expression of IFN- $\gamma$ and tumour necrosis factor TNF- $\alpha$ was seen in lesions that presented later than 6 months from the time of infection [33]. Also, a case-control study conducted by Samaranayake et al. [35] suggested particular human leukocyte antigen (HLA) genes may have a role in determining the predisposition to localized CL.

A study identified enhanced susceptibility to CL among the Sinhalese and/or specific individuals. This higher susceptibility than other ethnic groups may determine by 

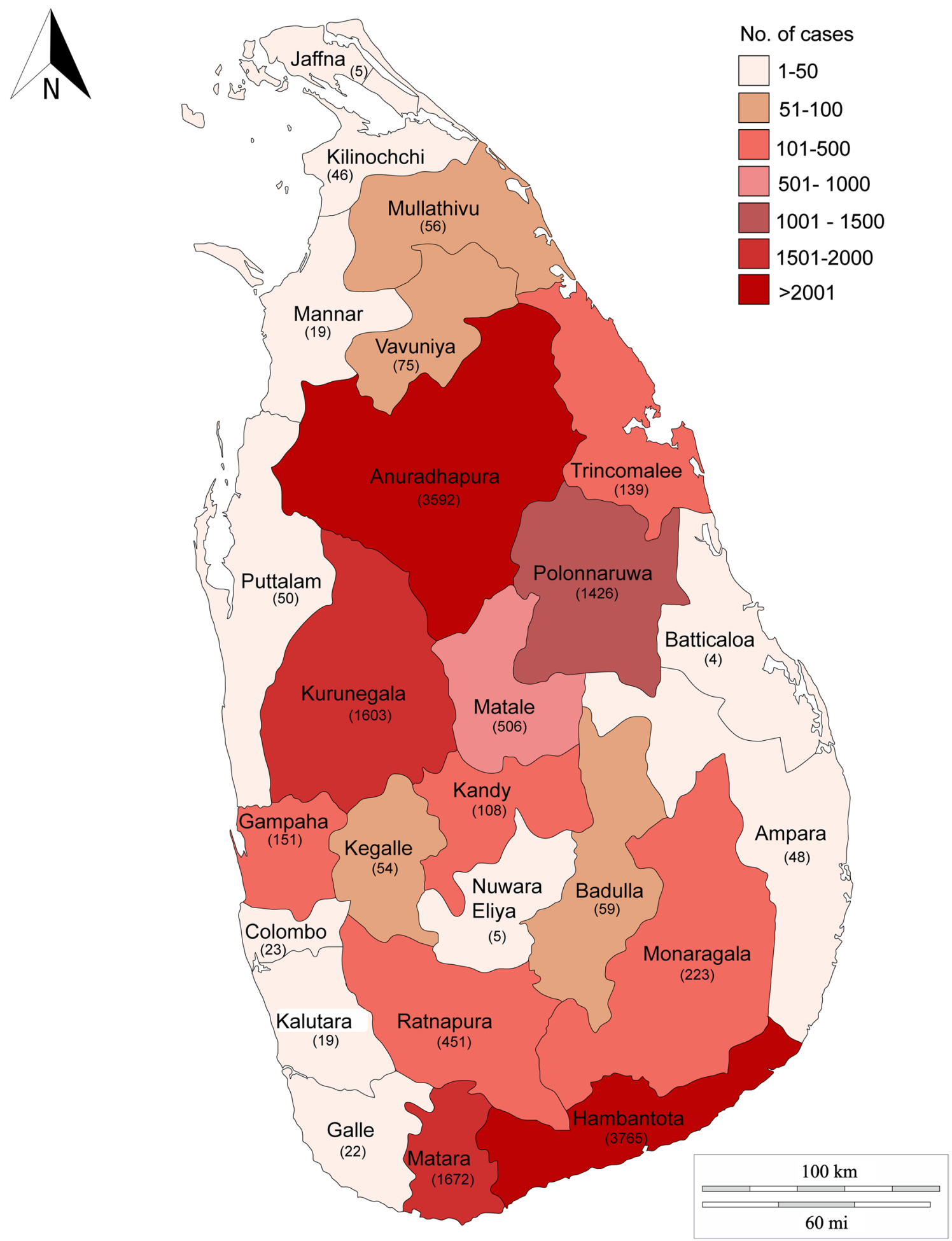

Fig. 1 Total number of leishmaniasis cases reported from each district in Sri Lanka from January 2009 to May 2019 (Epidemiology Unit, Ministry of Health, Sri Lanka)

genetic factors [36]. Further work is required to completely identify important genetic characteristics in humans that are associated with increased susceptibility to CL infection $[35,37]$.

\section{Vector}

Several different species of sandflies transmit leishmaniasis. Presence of all three sandfly species in the Argentipes 


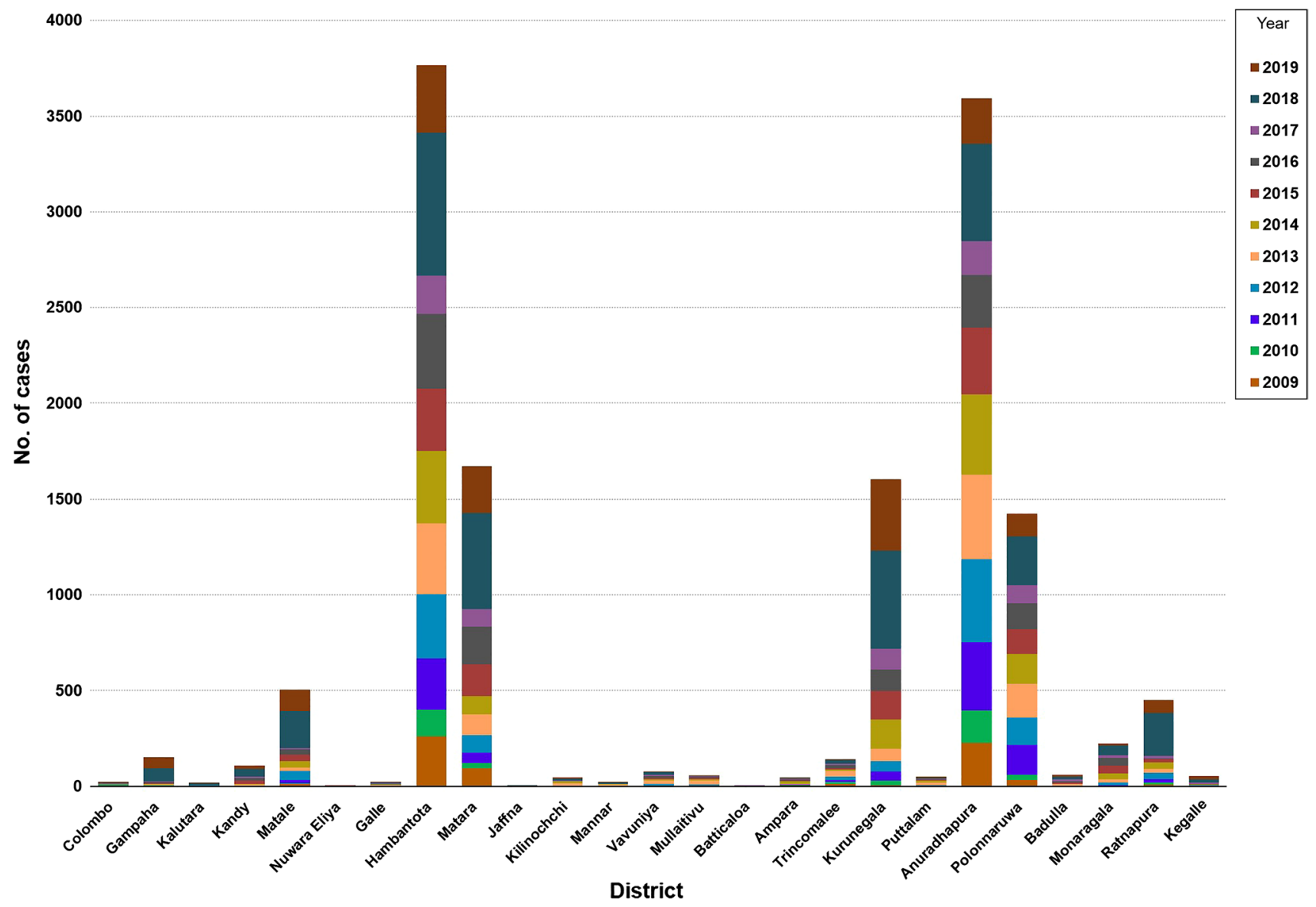

Fig. 2 Number of leishmaniasis case reported in each year from 2009 to May 2019 referring to each district (Epidemiology Unit, Ministry of Health, Sri Lanka). Districts are given in the $X$-axis, and the number of cases is given in the $Y$-axis

complex, viz. Phlebotomus annandalei, Phlebotomus argentipes sensu stricto, and Phlebotomus glaucus were recorded from the country $[38,39]$. In 2011, a study provided the first evidence to establish $P$. argentipes (Diptera: Psychodidae) as the transmitting agent of leishmaniasis in Sri Lanka [40].

Phlebotomus argentipes is the primary vector of VL in India [41] and the same species act as the vector to transmit CL in Sri Lanka. $P$. argentipes is a widely prevalent insect in almost all parts of the island [4, 38, 42]. Another species identified is $P$. stantoni, a jungle species feeding on wild rodents. However, it is not suspected as a vector of Leishmania [10, 31, 43]. Presence of $P$. salehi (mesghali): a potential CL vector from the subgenus Phlebotomus was reported from the dry zone [44]. The other two species reported in the subgenus, $P$. papatasi (Scopoli), and P. bergeroti (Parrot) have not yet been reported from Sri Lanka [44].

Except for a few minor dissimilarities, the morphology of the sandflies in Sri Lanka is similar to the sandflies found in Pakistan [44]. Furthermore, species identity confirmed with the DNA barcoding is compatible with the current morphology-based identification [45]. A study reported two morphospecies; A and B of $P$. argentipes sensu lato (s.1.) [46]. Also, after reassessing the taxonomy of the Sri Lankan Argentipes complex, two sibling species were proposed. Sibling species A was incriminated as a vector for CL and possibly for $\mathrm{VL}$ [47]. Furthermore, a new sibling population of the P. argentipes s.l. species complex in central Sri Lanka was identified [48]. Due to this complex species diversity, their evolutionary differences, relative vector capacities, and their disease transmission potentials should be investigated.

In 2011, Gajapathy and Surendran [49] identified the rich diversity of Sergentomia species in Sri Lanka that may have a possible role in the transmission of leishmaniasis. Sergentomia zeylanica is suspected as the primary vector for CL in Dikwella region in southern Sri Lanka [50]. Presence of this species in other districts in Sri Lanka should be investigated to identify it as a possible vector for CL. 


\section{Reservoir Hosts}

Definite reservoir host for leishmaniasis in Sri Lanka has not yet been identified [51]. However, CL patients with active lesions can be considered as possible reservoir hosts $[17,28]$. Serological findings attest there is a possibility that dogs may act as reservoir hosts [52, 53]. Likelihood of rodents being reservoir hosts was also considered; however, no evidence was found [52]. In addition, a study identified evidence in favour of zoonotic transmission of the local species [54]. With such indications, the initial view of anthroponotic $L$. donovani transmission is being questioned. However, whether the transmission is anthroponotic, zoonotic or both are not confirmed thus far and, therefore, further studies are needed to confirm. Also, it is required to identify and confirm the possible reservoir hosts for leishmaniasis in Sri Lanka.

\section{Risk Factors and High-Risk Groups}

Several demographic characteristics are associated with high risk. Adults are at high risk than children due to their outdoor occupations and infections are common among young adults $[9,51]$. Males are more affected than females $[9,27,28]$. These demographic characteristics of the patients are only studied in some areas of the country, mainly focusing on the endemic regions [9, 30, 51]. However, the infections are reported in all the districts in Sri Lanka. Therefore, a broad study can be carried out as a national program concerning all the districts to identify the demographic characteristics associated with leishmaniasis infections.

Certain occupations are associated with increased CL infections. Unmonitored cattle breeding and living near paddy fields are associated with increased transmission of CL $[29,31,55]$. People in the dry and the intermediate climatic zones in Sri Lanka are mainly paddy farmers and are involved with the Chena cultivation during the daytime. These agricultural activities are, in many cases associated with irrigation systems and moisture-rich soil. These conditions facilitate favourable resting and breeding habitats for sand flies, thus increasing the risk of infection [56]. Uncovered areas in the body are more prone to sandfly bites [8]. Infected areas of the patients' body show a clear association with the clothing habits in the Sri Lankan society. Most of the farmers in the endemic areas wear clothes to cover only the lower part of the body [8]. Therefore, the exposure of sandfly bites to the upper part of the body is higher compared to the lower parts [57]. Underprivileged living conditions and house clustering also increase the risk of infection. Low usage of protective measures against insect bites is associated with increased infections [58].

In addition, employees in the armed forces have been identified as a high-risk group to leishmaniasis [51]. Relocation of the armed forces into previously uninhabited areas in the North and North Central provinces during the civil war increased risk of acquiring leishmaniasis infection [25, 30].

\section{Diagnosis}

Direct microscopic examination is the primary technique used to diagnose leishmaniasis in Sri Lanka. Giemsastained smears are being microscopically examined under oil immersion $(\times 1000)$ to identify Leishmania amastigotes [59]. Some CL patients have promastigote-like structures in their skin smears. Therefore, during the microscopic examinations, identification of the different morphometric features of amastigotes may be useful for the diagnosis of CL in clinically suspected patients [60]. Furthermore, it is essential to consider scaly skin lesions with erythema and lack of pruritus along with other features in the clinical diagnosis of CL [28].

The level of accuracy obtained with smears performed locally is sufficient for the diagnosis of CL in endemic areas [61]. However, the sensitivity of the direct microscopic method is only $60-70 \%$ [62]. Also, this method requires professional skills and training. Therefore, a program is required to increase the expertise of healthcare professionals on how to use direct microscopy method to diagnose leishmaniasis. They should be knowledgeable about the morphological features of the amastigotes and promastigotes. In addition, they should know how to observe a smear using the correct methods.

Molecular methods are used to diagnose leishmaniasis due to high sensitivity and efficiency. Sri Lankan CL can be diagnosed and identified accurately up to species level by Leishmania PCR assays. PCR is essential for epidemiological studies in areas where skin tuberculosis and leprosy coexist with leishmaniasis [47,63]. Also, the diagnosis of the patients suspected for VL and MCL should be confirmed by PCR and culture [61]. Negative skin slit smears are recommended to combine with PCR for confirmation [64]. Loop-mediated isothermal amplification (LAMP) assay optimized under the local conditions can also be used as a diagnostic tool. However, due to its low sensitivity, confirmation with nested PCR is required [65]. Nevertheless, the cost of LAMP assay is less than that of PCR. Moreover, the LAMP assay requires basic laboratory facilities while molecular diagnostic methods including PCR require wellestablished laboratories [65].

Furthermore, a recent study has developed a $100 \%$ sensitive, Leishmania spp. specific modified version of a nested 
PCR (Mo-STNPCR). This method can be used to confirm the diagnosis of microscopy and in vitro culture-negative clinically suggestive cases [66]. However, the cost of the Mo-STNPCR is higher than that of light microscopy and in vitro culture [66].

Culture techniques are also being applied to the diagnosis of leishmaniasis. The first successful isolation of the local Leishmania sp. by in vitro culture was reported in 2002 [59]. The first successful in vitro culture of Leishmania spp. causing autochthonous VL in Sri Lanka was in 2011 [14]. Microcapillary culture can be used for the diagnosis and initial isolation of the Leishmania under minimum facilities [67, 68]. However, the Sri Lankan Leishmania strain has a prolonged growth rate and low multiplication rates. Therefore, the use of culture techniques for isolation and identification is not recommended [18].

Sri Lankan $L$. donovani strain shows low expression of peroxidoxin antigen in amastigotes and low parasite counts in skin lesions. Therefore, a currently available commercial kit; the rapid diagnostic immunochromatographic strip (CLDetect $^{\text {TM }}$ IC-RDT) is not successful in the diagnosis of CL in Sri Lankan patients [64]. Thus, the development of a rapid diagnostic tool to detect $L$. donovani strain in Sri Lanka is an essential requirement to diagnose CL more efficiently.

\section{Treatments}

Sodium stibogluconate and liquid Nitrogen cryotherapy are being used to treat CL in Sri Lanka [17, 69]. Cryotherapy is shown to be effective because all Leishmania spp. are thermosensitive. Treatment with liquid Nitrogen does not cause any systemic side effects. This treatment method is simple and comparatively inexpensive [17, 69]. Intralesional hypertonic sodium chloride (HS) is also effective against CL, and safe concentration of HS for this treatment has been identified. Further studies are recommended to identify more safe HS concentrations to treat CL [70, 71].

Although cryotherapy is the primary CL treatment used in Sri Lanka, it is not recommended to apply to face due to scarring. Also, cryotherapy cannot be used to the patients that tend to develop keloids [69]. Furthermore, some patients have shown low compliance with cryotherapy and smear positivity for a prolonged period after the treatment [55]. Atypical lesions seem to demonstrate a delayed response to the first line anti-leishmanial treatment [12].

Furthermore, the local $L$. donovani variants may undergo genetic changes which could result in unfavourable clinical and epidemiological results [9]. Therefore, persistence in work to identify genetic variances and any resistance to treatments shown by local $L$. donovani species is necessary to develop appropriate treatments.

\section{Prevention and Control}

Control measures that are currently employed include early identification and treatments $[17,70]$. Some sandfly control programs are only conducted in endemic areas when there is an outbreak. However, Leishmania infections have been reported in all the districts in Sri Lanka (Fig. 1). Therefore, a holistic approach is required to control the sandfly species more effectively.

Sandfly control measures should be carefully launched because biochemical assays revealed acetylcholinesterase and esterase-based insecticide resistance mechanisms in sandflies [72]. Consequently, insect control by organophosphorus and carbamate insecticides may have already been compromised [72]. Additionally, antimalarial campaigns in Sri Lanka used many insecticide sprays until 1960s. After elimination of malaria infections in the country, insecticide spraying activities were discontinued. This may also be a reason for the increased sandfly population and thus the gradual and silent increment in the infection [9]. Also, it could have triggered resistance mechanisms against insecticides. Therefore, a broad study concerning all the sandfly species that have a possible role in transmitting leishmaniasis and their resistance mechanisms is required before applying any sandfly control measures.

Still, the reservoir hosts, and whether the L. donovani transmission is anthroponotic, zoonotic or both are not identified in Sri Lanka. Inadequacy of research in these fields has made it challenging to launch more effective leishmaniasis disease control campaigns.

It is essential to increase public awareness about Leishmania infection based on health education and surveillance $[17,27,73]$. The majority of healthcare workers have adequate knowledge of Leishmania infections [74]. Increasing the public awareness to change the clothing habits as well as to be aware of the insect bites will lower the leishmaniasis prevalence. A broad study should be carried out to identify the demographic characteristics and behaviours that would increase the risk of acquiring leishmaniasis. This information, in return, would facilitate the awareness programs that must be conducted island wide and mainly target the high-risk demographic groups. Also, developing the housing and sanitary conditions of the people who live in affected areas will reduce the infection.

\section{Conclusions}

Leishmaniasis has become a critically important parasitic infection in Sri Lanka, whereas the significant clinical form is cutaneous leishmaniasis. There is plausible 
evidence to believe that the prevalence of visceral leishmaniasis would increase. Prevalence of the leishmaniasis infections is reported from all the districts of the country, including the endemic areas: north-central, north-western and southern regions of Sri Lanka. Complex genetic and the population diversity of both the parasites and vectors make the control of this disease very difficult. Therefore, more studies are essential to be carried out to fill up the existing knowledge gaps emphasized in this review. Information obtained from these work will facilitate the development of effective diagnostic tools, treatment methods, successful disease prevention, and control programs.

\section{References}

1. McGwire BS, Satoskar AR (2014) Leishmaniasis: clinical syndromes and treatment. QJM 107:7-14. https://doi.org/10.1093/ qjmed/hct116

2. Torres-Guerrero E, Quintanilla-Cedillo MR, Ruiz-Esmenjaud J, Arenas R (2017) Leishmaniasis: a review. F1000Res 6:1-15. https ://doi.org/10.12688/f1000research.11120.1

3. Reithinger R, Dujardin JC, Louzir H, Pirmez C, Alexander B, Brooker S (2007) Cutaneous leishmaniasis. Lancet Infect Dis 7:581-596. https://doi.org/10.1016/S1473-3099(07)70209-8

4. Siriwardana HV, Chandrawansa PH, Sirimanna G, Karunaweera ND (2012) Leishmaniasis in Sri Lanka: a decade old story. Sri Lankan J Infect Dis 16:2-12. https://doi.org/10.4038/sljid .v2i2.4420

5. Karunaweera ND, Pratlong F, Siriwardane HV, Ihalamulla RL, Dedet JP (2003) Sri Lankan cutaneous leishmaniasis is caused by Leishmania donovani zymodeme MON-37. Trans R Soc Trop Med Hyg 97:380-381. https://doi.org/10.1016/S0035 -9203(03)90061-7

6. Epidemiology Unit, Ministry of Health, Sri Lanka, Epidemiology of Leishmaniasis (Part II). Weekly epidemiology report 2019, vol 48, no 8

7. Khalil EA, Weldegebreal T, Younis BM, Omollo R, Musa AM, Hailu W, Abuzaid AA, Dorlo TP, Hurissa Z, Yifru S, Haleke W (2014) Safety and efficacy of single dose versus multiple doses of Am Bisome ${ }^{\circledR}$ for treatment of visceral leishmaniasis in eastern Africa: a randomised trial. PLoS Negl Trop Dis 8:e2613

8. Nawaratna SS, Weilgama DJ, Wijekoon CJ, Dissanayake M, Rajapaksha K (2007) Cutaneous leishmaniasis, Sri Lanka. Emerg Infect Dis 13:1068-1070. https://doi.org/10.3201/eid1307.06077 3

9. Siriwardana Y, Deepachandi B, Weliange SD, Udagedara C, Wickremarathne C, Warnasuriya W, Ranawaka RR, Kahawita I, Chandrawansa PH, Karunaweera ND (2019) First evidence for two independent and different leishmaniasis transmission foci in Sri Lanka: recent introduction or long-term existence? J Trop Med. https://doi.org/10.1155/2019/6475939

10. Athukorale DN, Seneviratne JK, Ihalamulla RL, Premaratne UN (1992) Locally acquired cutaneous leishmaniasis in Sri Lanka. Am J Trop Med Hyg 95:432-433 (PMID: 1460704)

11. Herath C, Ratnatunga N, Waduge R, Ratnayake P, Ratnatunga C, Ramadasa S (2010) A histopathological study of cutaneous leishmaniasis in Sri Lanka. Ceylon Med J 55:106-111. https:// doi.org/10.1371/journal.pntd.0002613

12. Siriwardana Y, Deepachandi B, Gunasekara C, Warnasooriya W, Karunaweera ND (2019) Leishmania donovani induced cutaneous leishmaniasis: an insight into atypical clinical variants in Sri Lanka. J Trop Med. https://doi.org/10.1155/2019/4538597

13. Abeygunasekara PH, Costa YJ, Seneviratne N, Ratnatunga N, Wijesundera M (2009) Locally acquired visceral leishmaniasis in Sri Lanka. Ceylon Med J 52:30-31. https://doi.org/10.4038/cmj. v52i1.1047

14. Ranasinghe PH, Abeygunasekera PH, Athauda SB, Chandrasekharan NV, Mendis AS, Hulangamuwa CS, Wickremasinghe DR (2011) First successful in vitro culture of Leishmania sp. causing autochthonous visceral leishmaniasis in Sri Lanka. Ceylon Med J 56:179-180 (PMID: 22298217)

15. Ranasinghe $\mathrm{S}$, Zhang WW, Wickremasinghe R, Abeygunasekera $\mathrm{P}$, Chandrasekharan V, Athauda S, Mendis S, Hulangamuwa S, Matlashewski G, Pratlong F (2012) Leishmania donovani zymodeme MON-37 isolated from an autochthonous visceral leishmaniasis patient in Sri Lanka. Pathog Glob Health 106:421-424. https://doi.org/10.1179/2047773212Y.0000000054

16. Siriwardana HD, Karunanayake P, Goonerathne L, Karunaweera ND (2017) Emergence of visceral leishmaniasis in Sri Lanka: a newly established health threat. Pathog Glob Health 111:317-326. https://doi.org/10.1080/20477724.2017.1361564

17. Siriwardana HY, Noyes HA, Beeching NJ, Chance ML, Karunaweera ND, Bates PA (2007) Leishmania donovani and cutaneous leishmaniasis, Sri Lanka. Emerg Infect Dis 13:476478. https://doi.org/10.3201/eid1303.060242

18. Yatawara L, Le TH, Wickramasinghe S, Agatsuma T (2008) Maxicircle (mitochondrial) genome sequence (partial) of Leishmania major: gene content, arrangement and composition compared with Leishmania tarentolae. Gene 424:80-86. https://doi.org/10.1016/j. gene.2008.07.026

19. Rajapaksa US, Ihalamulla RL, Karunaweera ND (2005) First report of mucosal tissue localisation of leishmaniasis in Sri Lanka. Ceylon Med J50:90-91 (PMID: 16114778)

20. Rathnayake D, Ranawake RR, Sirimanna G, Siriwardhane Y, Karunaweera N, De Silva R (2010) Co-infection of mucosal leishmaniasis and extra pulmonary tuberculosis in a patient with inherent immune deficiency. Int J Dermatol 49:549-551. https:// doi.org/10.1111/j.1365-4632.2010.04376.x

21. Sethuraman G, Sharma VK (2008) Indian mucosal leishmaniasis due to Leishmania donovani infection. N Engl J Med 358:313315. https://doi.org/10.1056/NEJMc072391

22. Zhang WW, Ramasamy G, McCall LI, Haydock A, Ranasinghe S, Abeygunasekara P, Sirimanna G, Wickremasinghe R, Myler P, Matlashewski G (2014) Genetic analysis of Leishmania donovani tropism using a naturally attenuated cutaneous strain. PLoS Pathog 10:e1004244. https://doi.org/10.1371/journal.ppat.1004244

23. Kariyawasam KK, Selvapandiyan A, Siriwardana HV, Dube A, Karunanayake P, Senanayake SA, Dey R, Gannavaram S, Nakhasi HL, Karunaweera ND (2018) Dermotropic Leishmania donovani in Sri Lanka: visceralizing potential in clinical and preclinical studies. Parasitology 145:443-452. https://doi.org/10.1017/S0031 18201700169X

24. McCall LI, Zhang WW, Ranasinghe S, Matlashewski G (2013) Leishmanization revisited: immunization with a naturally attenuated cutaneous Leishmania donovani isolate from Sri Lanka protects against visceral leishmaniasis. Vaccine 31:1420-1425. https ://doi.org/10.1016/j.vaccine.2012.11.065

25. Siriwardana HVYD, Thalagala N, Karunaweera ND (2010) Clinical and epidemiological studies on the cutaneous leishmaniasis caused by Leishmania (Leishmania) donovani in Sri Lanka. Ann Trop Med Parasitol 104:213-223. https://doi.org/10.1179/13648 $5910 X 12647085215615$

26. Galgamuwa LS, Dharmaratne SD, Iddawela D (2018) Leishmaniasis in Sri Lanka: spatial distribution and seasonal variations from 2009 to 2016. Parasites Vectors 11:60. https://doi.org/10.1186/ s13071-018-2647-5 
27. Sandanayaka R, Kahawita I, Gamage A, Siribaddana S, Agampodi $S$ (2014) Emergence of cutaneous leishmaniasis in Polonnaruwa, Sri Lanka 2008-2011. Trop Med Int Health 19:140-145. https:// doi.org/10.1111/tmi.1223

28. Iddawela D, Vithana SM, Atapattu D, Wijekoon L (2018) Clinical and epidemiological characteristics of cutaneous leishmaniasis in Sri Lanka. BMC Infect Dis. https://doi.org/10.1186/s1287 9-018-2999-7

29. Chandrawansa PH, Ratnayake RM, Ratnayake PL (2008) Cutaneous leishmaniasis-an emerging threat. J Ruhunu Clin Soc 15:20-24

30. Semage SN, Pathirana KP, Agampodi SB (2014) Cutaneous leishmaniasis in Mullaitivu, Sri Lanka: a missing endemic district in the leishmaniasis surveillance system. Int J Infect Dis 25:53-55. https://doi.org/10.1016/j.ijid.2014.03.1382

31. Rajapaksa US, Ihalamulla RL, Udagedera C, Karunaweera ND (2007) Cutaneous leishmaniasis in southern Sri Lanka. Trans R Soc Trop Med Hyg 101:799-803. https://doi.org/10.1016/j.trstm h.2006.05.013

32. Hlavacova J, Votypka J, Volf P (2013) The effect of temperature on Leishmania (Kinetoplastida: Trypanosomatidae) development in sand flies. J Med Entomol 50:955-958. https://doi.org/10.1603/ ME13053

33. Manamperi NH, Oghumu S, Pathirana N, de Silva MV, Abeyewickreme W, Satoskar AR, Karunaweera ND (2017) In situ immunopathological changes in cutaneous leishmaniasis due to Leishmania donovani. Parasite Immunol 39:e12413. https://doi. org/10.1111/pim.12413

34. Galgamuwa LS, Sumanasena B, Iddawela D, Wickramasinghe S, Yatawara L (2019) Assessment of intralesional cytokine profile of cutaneous leishmaniasis caused by Leishmania donovani in Sri Lanka. BMC Microbiol. https://doi.org/10.1186/s1286 6-018-1384-4

35. Samaranayake N, Fernando SD, Neththikumara NF, Rodrigo C, Karunaweera ND, Dissanayake VH (2016) Association of HLA class I and II genes with cutaneous leishmaniasis: a case control study from Sri Lanka and a systematic review. BMC Infect Dis 16:292. https://doi.org/10.1186/s12879-016-1626-8

36. Samaranayake TN, Dissanayake VH, Fernando SD (2008) Clinical manifestations of cutaneous leishmaniasis in Sri Lanka-possible evidence for genetic susceptibility among the Sinhalese. Ann Trop Med Parasitol 102:383-390. https://doi.org/10.1179/136485908X 300779

37. Samaranayake TN, Fernando SD, Dissanayake VH (2010) Candidate gene study of susceptibility to cutaneous leishmaniasis in Sri Lanka. Trop Med Int Health 15:632-638. https://doi.org/10.1 $111 / j .1365-3156.2010 .02491 . x$

38. Surendran SN, Kajatheepan A, Ramasamy R (2007) Socioenvironmental factors and sandfly prevalence in Delft Island, Sri Lanka: implications for leishmaniasis vector control. J Vector Borne Dis 44:65-68

39. Gajapathy K, Jude PJ, Surendran SN (2011) Morphometric and meristic characterization of Phlebotomus argentipes species complex in northern Sri Lanka: evidence for the presence of potential leishmaniasis vectors in the country. Trop Biomed 28:259-268

40. Senanayake SA, Abeyewickreme W, Abeysinghe RR, Dotson EM, Karunaweera ND (2011) Phlebotomus argentipes: possible vector of leishmaniasis in Sri Lanka. Annual research symposium, University of Colombo, Sri Lanka, OP1

41. Kishore K, Kumar V, Kesari S, Dinesh DS, Kumar AJ, Das P, Bhattacharya SK (2006) Vector control in leishmaniasis. Indian J Med Res 123:467

42. Lane RP, Pile MM, Amerasinghe FP (1990) Anthropophagy and aggregation behaviour of the sandfly Phlebotomus argentipes in Sri Lanka. Med Vet Entomol 4:79-88. https://doi. org/10.1111/j.1365-2915.1990.tb00263.x
43. Naotunne TD, Rajakulendran S, Abeywickreme W, Kulasiri CD, Perera J, Premaratne UN, Attygalle D, Mendis KN (1990) Cutaneous leishmaniasis in Sri Lanka. An imported disease linked to the Middle East and African employment boom. Trop Geogr Med 42:72-74 (PMID: 2260200)

44. Gajapathy K, Surendran SN (2012) Report of the presence of Phlebotomus (Phlebotomus) salehi Mesghali in Sri Lanka: a potential cutaneous leishmaniasis vector. J Natl Sci Found Sri Lanka 40:169-173

45. Gajapathy K, Tharmasegaram T, Eswaramohan T, Peries LB, Jayanetti R, Surendran SN (2016) DNA barcoding of Sri Lankan phlebotomine sand flies using cytochrome c oxidase subunit I reveals the presence of cryptic species. Acta Trop 161:1-7. https ://doi.org/10.1016/j.actatropica.2016.05.001

46. Surendran SN, Kajatheepan A, Hawkes NJ, Ramasamy R (2005) First report on the presence of morphospecies A and B of Phlebotomus argentipes sensu lato (Diptera: Psychodidae) in Sri Lankaimplications for leishmaniasis transmission. J Vector Borne Dis 42:155-158

47. Gajapathy K, Peiris LB, Goodacre SL, Silva A, Jude PJ, Surendran SN (2013) Molecular identification of potential leishmaniasis vector species within the Phlebotomus (Euphlebotomus) argentipes species complex in Sri Lanka. Parasites Vectors. https://doi. org/10.1186/1756-3305-6-302

48. Ranasinghe S, Maingon RD, Bray DP, Ward RD, Udagedara C, Dissanayake M, Jayasuriya V, de Silva NK (2012) A morphologically distinct Phlebotomus argentipes population from active cutaneous leishmaniasis foci in central Sri Lanka. Mem Inst Oswaldo Cruz 107:402-409. https://doi.org/10.1590/S0074-0276201200 0300016

49. Gajapathy K, Surendran SN (2011) Morphometric description of Sand flies belong to Genus Sergentomyia (Sergentomyia) (Diptera; Psychodidae; Phlebotominae) in Sri Lanka; evidence for the presence of Sergentomyia (Sergentomyia) pondicherriensis \& amp; Sergentomyia (Sergentomyia) dentata in the Country. J Entomol 8:512-529. https://doi.org/10.3923/je.2011.512.529

50. Premachandra WD, Senarath DP, De Silva MP, Peiris BL (2012) A study on phlebotomine sandflies (Diptera: Phlebotomidae) in Dickwella, southern Sri Lanka, an endemic focus for cutaneous leishmaniasis. Int J Trop Insect Sci 32:32-38. https://doi. org/10.1017/s174275841200001x

51. Galgamuwa LS, Sumanasena B, Yatawara L, Wickramasinghe S, Iddawela D (2017) Clinico-epidemiological patterns of cutaneous leishmaniasis patients attending the Anuradhapura teaching hospital, Sri Lanka. Korean J Parasitol 55:1-7. https://doi.org/10.3347/ kjp.2017.55.1.1

52. Nawaratna SS, Weilgama DJ, Rajapaksha K (2009) Cutaneous leishmaniasis in Sri Lanka: a study of possible animal reservoirs. Int J Infect Dis 13:513-517. https://doi.org/10.1016/j. ijid.2008.08.023

53. Rosypal AC, Tripp S, Kinlaw C, Hailemariam S, Tidwell RR, Lindsay DS, Rajapakse RP, Sreekumar C, Dubey JP (2010) Surveillance for antibodies to Leishmania spp. in dogs from Sri Lanka. J Parasitol 96:230-231. https://doi.org/10.1645/GE-2288

54. Siriwardana HV, Noyes HA, Beeching NJ, Wickremasinghe AR, Chance ML, Bates PA, Karunaweera ND (2008) Clinical features of cutaneous leishmaniasis in Sri Lanka and molecular identification of $L$. donovani as the cause. In: 13th international congress on infectious diseases, p e387. https://doi.org/10.1016/j. ijid.2008.05.1023

55. Siriwardena HVYD, Udagedara CU, Karunaweera ND (2003) Clinical features, risk factors and efficacy of cryotherapy in cutaneous leishmaniasis in Sri Lanka. Ceylon Med J 48:10-12

56. Ranasinghe S, Wickremasinghe R, Munasinghe A, Hulangamuwa S, Sivanantharajah S, Seneviratne K, Bandara S, Athauda I, Navaratne C, Silva O, Wackwella H (2013) Cross-sectional study to 
assess risk factors for leishmaniasis in an endemic region in Sri Lanka. Am J Trop Med Hyg 89:742-749. https://doi.org/10.4269/ ajtmh.12-0640

57. Ranawaka RR, Weerakoon HS (2010) Randomized, double-blind, comparative clinical trial on the efficacy and safety of intralesional sodium stibogluconate and intralesional $7 \%$ hypertonic sodium chloride against cutaneous leishmaniasis caused by L. donovani. J Dermatol Treat 21:286-293. https://doi.org/10.3109/0954663090 3287445

58. Kariyawasam KK, Edirisuriya CS, Senerath U, Hensmen D, Siriwardana HV, Karunaweera ND (2015) Characterisation of cutaneous leishmaniasis in Matara district, southern Sri Lanka: evidence for case clustering. Pathog Glob Health 109:336-343. https://doi. org/10.1179/2047773215Y.0000000032

59. Ihalamulla RL, Siriwardana HV, Gamage S, Perera AJ, Karunaweera ND (2002) First successful in vitro culture of autochthonous Leishmania sp. in Sri Lanka. Ceylon Med J: https ://doi.org/10.4038/cmj.v47i2.3454

60. Gunasekara A, Iddawela D, Wickramasinghe S (2019) Morphometrics of amastigote forms of Leishmania donovani in cutaneous leishmaniasis patients in Sri Lanka: evidence for the presence of promastigote-like structures. Sri Lankan J Infect Dis 9:59-67. https://doi.org/10.4038/sljid.v9i1.8238

61. Ranawaka RR, Abeygunasekara PH, Weerakoon HS (2013) Correlation of clinical, parasitological and histopathological diagnosis of cutaneous leishmaniasis in an endemic region in Sri Lanka. Ceylon Med J 57:149-152

62. Ramírez JR, Agudelo S, Muskus C, Alzate JF, Berberich C, Barker D, Velez ID (2000) Diagnosis of cutaneous leishmaniasis in Colombia: the sampling site within lesions influences the sensitivity of parasitologic diagnosis. J Clin Microbio 38:3768-3773 (PMID: 11015400)

63. Ranasinghe $\mathrm{S}$, Wickremasinghe R, Hulangamuwa S, Sirimanna G, Opathella N, Maingon RD, Chandrasekharan V (2015) Polymerase chain reaction detection of Leishmania DNA in skin biopsy samples in Sri Lanka where the causative agent of cutaneous leishmaniasis Leishmania donovani. Mem Inst Oswaldo Cruz 110:1017-1023. https://doi.org/10.1590/0074-02760150286

64. De Silva G, Somaratne V, Senaratne S, Vipuladasa M, Wickremasinghe R, Wickremasinghe R, Ranasinghe S (2017) Efficacy of a new rapid diagnostic test kit to diagnose Sri Lankan cutaneous leishmaniasis caused by Leishmania donovani. PLoS One 12:e0187024. https://doi.org/10.1371/journal.pone.0187024

65. Kothalawala HS, Karunaweera ND (2016) Loop-mediated isothermal amplification assay as a sensitive diagnostic tool for Leishmania donovani infections in Sri Lanka. Ceylon Med J 61:68-70. https://doi.org/10.4038/cmj.v61i2.8286
66. Deepachandi B, Weerasinghe S, Soysa P, Karunaweera N, Siriwardana Y (2019) A highly sensitive modified nested PCR to enhance case detection in leishmaniasis. BMC Infect Dis 19:623. https://doi.org/10.1186/s12879-019-4180-3

67. Ihalamulla RL, Rajapaksa US, Karunaweera ND (2005) Microculture for the isolation of Leishmania parasites from cutaneous lesions-Sri Lankan experience. Ann Trop Med Parasitol 99:571575. https://doi.org/10.1179/136485905X51364

68. Ihalamulla RL, Siriwardana HV, Karunaweera ND (2008) Efficacy of RPMI 1640 and M 199 media in the isolation of Leishmania from cutaneous lesions. Ann Trop Med Parasitol 102:173-175. https://doi.org/10.1179/136485908X252331

69. Ranawaka RR, Weerakoon HS, Opathella N (2011) Liquid nitrogen cryotherapy on Leishmania donovani cutaneous leishmaniasis. J Dermatol Treat 22:241-245. https://doi.org/10.3109/09546 631003762654

70. Ranawaka RR, Weerakoon HS, Opathella N, Subasinha C (2010) Leishmaniasis in the North central province, Sri Lanka-epidemiology and therapeutic response. Sri Lanka J Dermatol 14:4-8

71. Ranawaka RR, Weerakoon HS, de Silva SP (2015) Randomized, double-blind, controlled, comparative study on intralesional $10 \%$ and $15 \%$ hypertonic saline versus intralesional sodium stibogluconate in Leishmania donovani cutaneous leishmaniasis. Int J Dermatol 54:555-563. https://doi.org/10.1111/ijd.12685

72. Surendran SN, Karunaratne SH, Adamsn Z, Hemingway J, Hawkes NJ (2005) Molecular and biochemical characterization of a sand fly population from Sri Lanka: evidence for insecticide resistance due to altered esterases and insensitive acetylcholinesterase. Bull Entomol Res 95:371-380. https://doi.org/10.1079/ BER2005368

73. Ozbel Y, Sanjoba C, Alten B, Asada M, Depaquit J, Matsumoto Y, Demir S, Siyambalagoda RR, Rajapakse RP, Matsumoto Y (2011) Distribution and ecological aspects of sand fly (Diptera: Psychodidae) species in Sri Lanka. J Vector Ecol 36:S77-S86. https://doi.org/10.1111/j.1948-7134.2011.00115.x

74. Weerakoon SH, Ranawaka RR, Bandara WMP, Herath P, Warnasekara YPJN (2016) Knowledge on leishmaniasis among health care workers in an endemic area. Anuradhapura Med J 10:6-10. https://doi.org/10.4038/amj.v10i1.7597

Publisher's Note Springer Nature remains neutral with regard to jurisdictional claims in published maps and institutional affiliations. 